\title{
Healthy donor T cell responses to common cold coronaviruses and SARS-CoV-2
}

\author{
Bezawit A. Woldemeskel, ${ }^{1}$ Abena K. Kwaa, ${ }^{1}$ Caroline C. Garliss, ${ }^{1}$ Oliver Laeyendecker, ${ }^{1,2}$ Stuart C. Ray, ${ }^{1}$ and Joel N. Blankson ${ }^{1}$ \\ 'Department of Medicine, School of Medicine, Johns Hopkins University, Baltimore, Maryland, USA. ²Division of Intramural Research, National Institute of Allergy and Infectious Diseases (NIAID), NIH, \\ Baltimore, Maryland, USA.
}

\begin{abstract}
BACKCROUND. T cell responses to the common cold coronaviruses have not been well characterized. Preexisting T cell immunity to severe acute respiratory syndrome coronavirus 2 (SARS-CoV-2) has been reported, and a recent study suggested that this immunity was due to cross-recognition of the novel coronavirus by $T$ cells specific for the common cold coronaviruses.
\end{abstract}

\begin{abstract}
METHODS. We used the enzyme-linked immunospot (ELISPOT) assay to characterize the T cell responses against peptide pools derived from the spike protein of 3 common cold coronaviruses (HCoV-229E, HCoV-NL63, and HCoV-OC43) and SARSCoV-2 in 21 healthy donors (HDs) who were seronegative for SARS-CoV-2 and had no known exposure to the virus. An in vitro expansion culture assay was also used to analyze memory $\mathrm{T}$ cell responses.
\end{abstract}

\begin{abstract}
RESULTS. We found responses to the spike protein of the 3 common cold coronaviruses in many of the donors. We then focused on HCoV-NL63 and detected broad T cell responses to the spike protein and identified 22 targeted peptides. Interestingly, only 1 study participant had a significant response to SARS-CoV-2 spike or nucleocapsid protein in the ELISPOT assay. In vitro expansion studies suggested that T cells specific for the HCoV-NL63 spike protein in this individual could also recognize SARS-CoV-2 spike protein peptide pools.
\end{abstract}

CONCLUSION. HDs have circulating T cells specific for the spike proteins of HCoV-NL63, HCoV-229E, and HCoV-OC43. T cell responses to SARS-CoV-2 spike and nucleocapsid proteins were present in only 1 participant and were potentially the result of cross-recognition by $\mathrm{T}$ cells specific for the common cold coronaviruses. Further studies are needed to determine whether this cross-recognition influences coronavirus disease 2019 (COVID-19) outcomes.

\section{Introduction}

There are 4 known human common cold coronaviruses (HCoV) that cause mild respiratory disease: HCoV-NL63, HCoV-229E, HCoV-OC43, and HCoV-HKU1 (1). Seroprevalence studies show that a large percentage of adults have been exposed to these viruses (2). Interestingly, surveillance studies have shown that reinfection with these viruses can occur $(3,4)$, suggesting that immunity is only partially protective. This theory is supported by a challenge study showing that study participants with lower titers of antibodies against $\mathrm{HCoV}-229 \mathrm{E}$ were infected and developed symptoms following experimental inoculation with the virus (5). Some of the same individuals could be reinfected by the same virus 1 year later, but they experienced minimal symptoms and had reduced periods of viral shedding (5). Despite these data, the $\mathrm{T}$ cell responses to these viruses in healthy donors (HDs) have not been characterized in an unbiased manner, and it is not known whether T cells contribute to the partial immunity described above.

Authorship note: BAW and AKK contributed equally to this work Conflict of interest: The authors have declared that no conflict of interest exists. Copyright: ( 2020, American Society for Clinical Investigation.

Submitted: August 7, 2020; Accepted: September 9, 2020; Published: November 16, 2020 Reference information: J Clin Invest. 2020;130(12):6631-6638.

https://doi.org/10.1172/JCl143120.
Severe acute respiratory syndrome coronavirus 2-specific (SARS-CoV-2-specific) $\mathrm{T}$ cell responses have been detected in patients with coronavirus disease 2019 (COVID-19) (6-20), and while $\mathrm{T}$ cell responses against SARS-CoV have been shown to be long lasting (8), it is not yet known whether SARS-CoV-2-specific $\mathrm{T}$ cells will confer protection against reinfection. Recent studies have suggested that preexisting $\mathrm{T}$ cell immunity to SARS-CoV-2 is present in some unexposed, HDs (6-11). However, other studies have found no evidence of SARS-CoV-2-specific $\mathrm{T}$ cells in unexposed individuals $(13,21)$. In this study, we sought to characterize the $\mathrm{T}$ cell responses to human cold coronaviruses and to determine whether preexisting immunity to SARS-CoV-2 was due to cross-recognition by $\mathrm{T}$ cells specific for endemic coronaviruses. To do this, we examined $\mathrm{T}$ cell responses to the spike (S) protein of 3 of the 4 common cold coronaviruses (HCoV-NL63, HCoV-229E, and $\mathrm{HCoV}-\mathrm{OC} 43$ ) and to SARS-CoV-2 in HDs with no known exposure to SARS-CoV-2. We then focused on HCoV-NL63 and identified what we believe to be 19 novel targeted peptides. We also examined the responses to the SARS-CoV-2 nucleocapsid (N) and membrane $(\mathrm{M})$ proteins and performed experiments to determine whether $\mathrm{T}$ cell cross-recognition of HCoV-NL63 and SARSCoV-2 S peptides was possible. We believe our results further the understanding of the immune response to coronaviruses and may have implications for SARS-CoV-2 vaccine trials. 

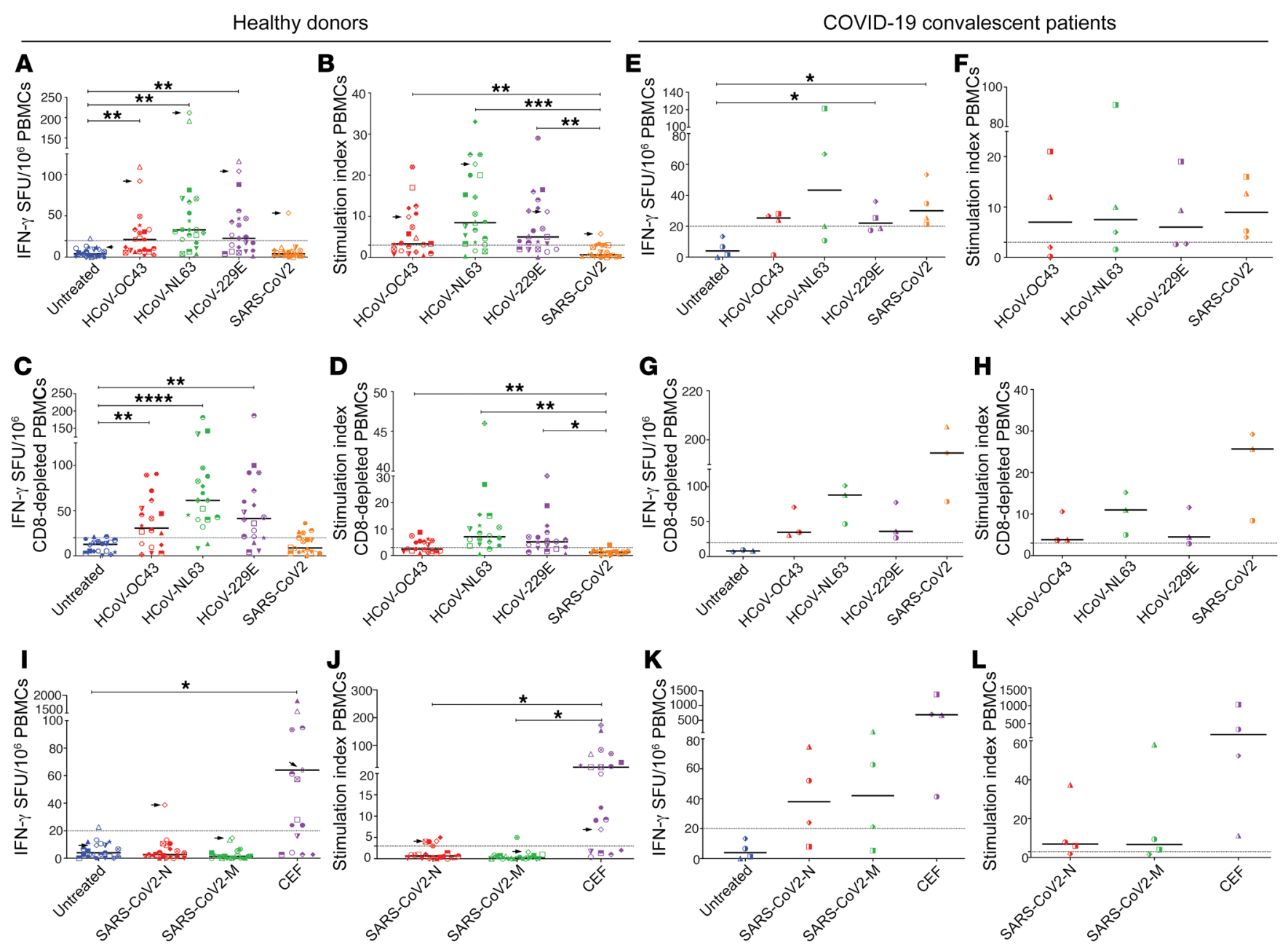

Figure 1. IFN- $\gamma$ responses to viral peptide pools from HDs and CCPs. The number of SFU from unfractioned PBMCs $(\mathbf{A}$ and $\mathbf{E})$ and CD8 ${ }^{+} \mathrm{T}$ cell-depleted PBMCs ( $C$ and $\mathbf{G}$ ) and the corresponding stimulation indices (B, $\mathbf{D}, \mathbf{F}$, and $\mathbf{H})$ in response to $S$ protein peptide pools from different viruses are shown. The number of SFU ( $\mathbf{I}$ and $\mathbf{K}$ ) and the stimulation indices ( $\mathbf{J}$ and $\mathbf{L}$ ) from unfractioned PBMCs in response to CEF and SARS-CoV-2 M and N peptide pools are also shown. Arrows indicate HD9. Each data point represents the mean of 3 replicate values. Horizontal bars represent the median. Statistical comparisons were performed using 1-way ANOVA with Geisser-Greenhouse correction and Dunnett's multiple-comparison test $(n=19-21$ for samples from HDs; $n=3-4$ for samples from patients with COVID-19). ${ }^{*} P=0.0332$, ${ }^{* *} P=0.0021,{ }^{* * *} P=0.0002$, and ${ }^{* * *} P<0.0001$.

\section{Results}

HDs have circulating $C D 4^{+} T$ cell responses to 3 common cold coronaviruses but not to SARS-CoV-2. For the purposes of this publication, the term "HDs" refers to individuals not previously exposed to SARS-Cov-2. To quantify responses in these individuals, we performed IFN- $\gamma$ ELISPOT assays to measure the frequency of $\mathrm{T}$ cells that secreted IFN- $\gamma$ in response to peptides from the $S$ protein from the common cold coronaviruses and SARS-CoV-2. A stimulation index (SI) was calculated by dividing the spot-forming units (SFU) per million PBMCs elicited by a peptide pool by the SFU present in wells treated with media alone. A positive response was defined as a SI of greater than 3 and an absolute value of greater than 20 SFU per million PBMCs. The median frequency of $\mathrm{T}$ cells reactive to $\mathrm{HCoV}-\mathrm{NL} 63, \mathrm{HCoV}-229 \mathrm{E}$, and $\mathrm{HCoV}-\mathrm{OC} 43 \mathrm{~S}$ proteins was 33, 23, and 21 cells per million PBMCs, respectively. In contrast, the median response to SARS-CoV-2 was just $3 \mathrm{~T}$ cells per million PBMCs, which was not statistically different from the response to media alone (Figure $1 \mathrm{~A}$ ). Of the $21 \mathrm{HDs}$ tested, 15,
10, and 10 individuals met both criteria for positive responses to HCoV-NL63, HCoV-229E, and HCoV-OC43 S peptides, respectively, whereas only 1 HD (HD9, indicated by the arrowheads in Figure 1) met both criteria for a positive response to the SARSCoV-2 $\mathrm{S}$ peptide pool (Figure 1B).

In order to determine whether $\mathrm{CD} 4^{+}$or $\mathrm{CD} 8^{+} \mathrm{T}$ cells were responding to the peptides, we depleted $\mathrm{CD} 8^{+} \mathrm{T}$ cells from $\mathrm{PBMCs}$ and used the residual cells in an ELISPOT assay. In virtually all study participants, $\mathrm{CD} 8^{+} \mathrm{T}$ cell depletion increased the number of SFU in all conditions. The median responses elicited by HCoVNL63, HCoV-229E, and HCoV-OC43 S peptide pools were 61, 41, and 31 SFU per million cells, respectively (Figure $1 \mathrm{C}$ ), and while the median responses to the SARS-CoV-2 S peptide pools were also higher, none of the participants met both the absolute count and the SI criteria for a positive response (Figure 1, C and D). In contrast, $\mathrm{T}$ cells from COVID-19 convalescent patients (CCPs) recognized peptide pools from the SARS-CoV-2 $\mathrm{S}$ protein (Figure $1, \mathrm{E}-\mathrm{H})$. The increase in responses to the common cold coronavi- 


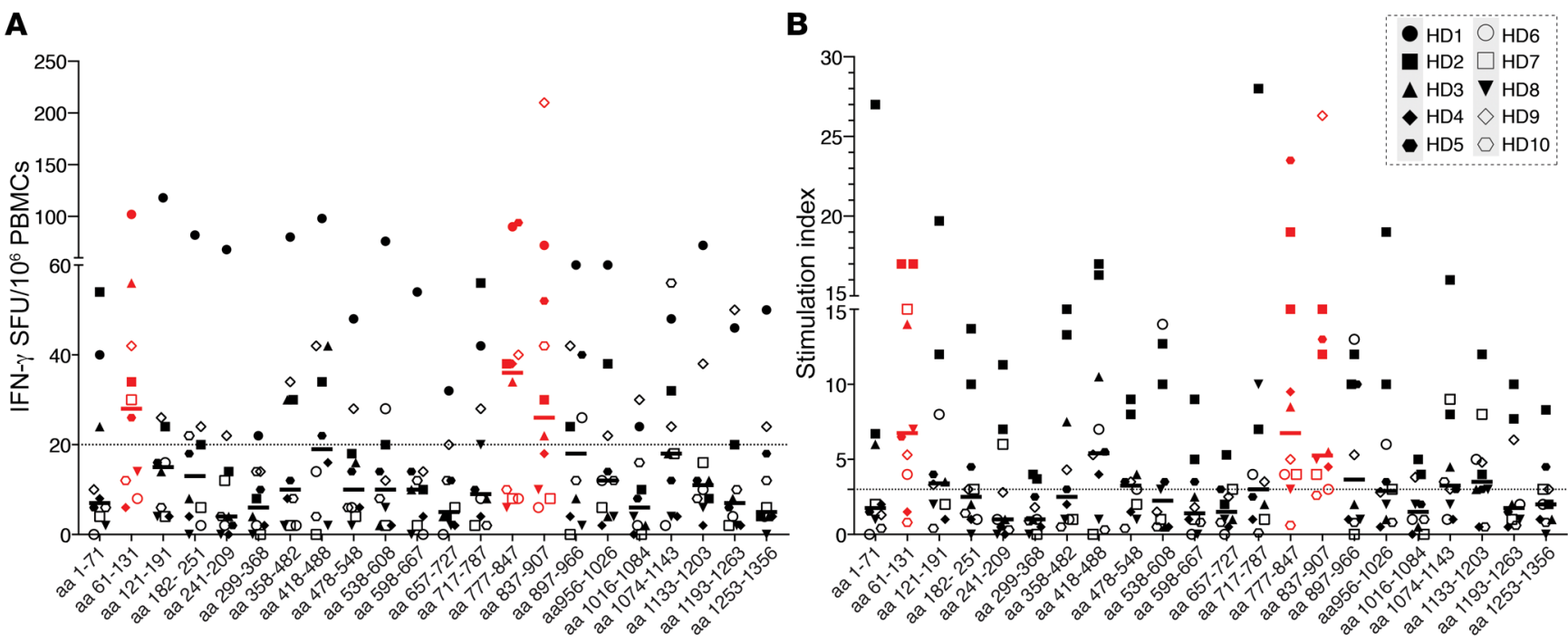

Figure 2. Breadth of T cell responses to HCoV-NL63 S protein. The numbers of SFU per million PBMCs (A) and stimulation indices (B) generated for pools of 10 peptides are shown for $10 \mathrm{HDs}$. Horizontal bars indicate the median. Pools that elicited the most potent responses are highlighted in red.

rus $\mathrm{S}$ peptide pools following $\mathrm{CD} 8^{+} \mathrm{T}$ cell depletion suggests that $\mathrm{CD}^{+} \mathrm{T}$ cells were the major effector cells in our assay, especially since depletion of $\mathrm{CD}^{+} \mathrm{T}$ cells abrogated the responses to $\mathrm{MHC}$ class I-restricted peptide pools from CMV, EBV, and influenza (CEF) (Supplemental Figure 1; supplemental material available online with this article; https://doi.org/10.1172/JCI143120DS1). However, it is likely that $\mathrm{CD} 4^{+} \mathrm{T}$ cells were more apt to be induced by the relatively long peptides used in our assay.

We then asked whether HD T cells were better able to recognize other SARS-CoV-2 peptides, including those from the $\mathrm{N}$ and $\mathrm{M}$ proteins. As shown in Figure 1, I and J, although the majority of HDs responded to CEF peptides, only HD9 had a robust response to peptides from the $\mathrm{N}$ protein, and no individual responded to peptides from the M protein. Although some of the other HDs had $\mathrm{T}$ cell responses that met the criteria for a positive response according to the SI, the absolute number of responding cells was less than the $20 \mathrm{SFU}$ cutoff. In contrast, T cells from 2 of the 4 CCPs recognized peptide pools from the SARS-CoV-2 M and N proteins (Figure $1, \mathrm{~K}$ and $\mathrm{L}$ ).

$T$ cells target various regions of the HCoV-NL63 S protein. The most robust $\mathrm{T}$ cell responses were directed against the $\mathrm{S}$ protein of HCoV-NL63, so we focused on this virus for epitope-mapping studies. In order to determine which regions of the $\mathrm{S}$ protein were targeted by HD T cells, we performed ELISPOT assays with sequential peptide pools consisting of 10 overlapping peptides. As shown in Figure 2, we observed broad responses to the $S$ peptide pools, and every pool was targeted by $\mathrm{T}$ cells from at least 1 individual. However, the most potent responses were elicited by pools 14 (amino acids 777-847), 2 (amino acids 61-131), and 15 (amino acids $837-907$ ), with a median of 36,28 , and $26 \mathrm{~T}$ cells producing IFN- $\gamma$, respectively (marked in red on Figure 2). In order to define the targeted peptides, we repeated the ELISPOT assay with individual peptides from the pools that were targeted by the $6 \mathrm{HDs}$ for whom we had sufficient numbers of PBMCs. Table 1 contains the list of the 22 peptides we were able to identify and the potential optimal epitopes and restricting HLA alleles. Interestingly, pep- tides 16 (amino acids 91-107), 132 (amino acids 783-799), and 141 (amino acids 837-853) were each targeted in 2 individuals.

Expansion of memory $\mathrm{T}$ cells and cross-recognition of $\mathrm{HCoV}$ NL63 and SARS-CoV-2 S protein peptide pools. We cultured PBMCs with peptide pools from different viral proteins to determine whether we could detect memory $\mathrm{CD} 4^{+} \mathrm{T}$ cell responses that were not seen when PBMCs were assayed directly after isolation. As shown in Figure 3, preculturing of PBMCs with the HCoV-NL63 S peptide pool caused an increase in the percentage of $\mathrm{HD}$ and $\mathrm{CCP}$ $\mathrm{CD} 4^{+} \mathrm{T}$ cells that coexpressed either IFN- $\gamma$ and IL-2 (Figure 3, A and B) or IFN- $\gamma$ and TNF- $\alpha$ (Figure 3, C and D) when the cells were restimulated with the same peptide pool. Interestingly, a modest but significant increase was also seen when cells from HDs were precultured and stimulated with SARS-CoV-2 S peptide pools, suggesting that memory responses to these peptides could be amplified in some HDs. HD9, the only individual who had a positive ELISPOT response to the SARS-CoV-2 peptide pool, also had the most robust memory $\mathrm{T}$ cell responses to both HCoV-NL63 and SARS-CoV-2 $S$ peptide pools. We performed the preculture expansion assay to determine whether cross-recognition could potentially explain this observation. As shown in Figure 4, PBMCs cultured in the absence of antigen for 10 days did not produce responses to HCoV-NL63 or SARS-CoV-2 S proteins or to the SARS-CoV-2 N protein that were above background levels (Figure 4A, plots 1-4) following a 12-hour restimulation with each peptide pool. In contrast, following 10 days of culturing with HCoV-NL63 S protein peptides, a 12-hour restimulation with the same peptides induced coexpression of IFN- $\gamma$ and IL- 2 from $1.25 \%$ of $\mathrm{CD}^{+}{ }^{+} \mathrm{T}$ cells, a 9.6fold increase over the response obtained when the cells were precultured without peptide (Figure 4A, plot 6 vs. plot 2). Interestingly, when cells that were cultured with the HCoV-NL63 S peptide pool for 10 days were restimulated with SARS-CoV-2 S peptides, we detected coexpression of IFN- $\gamma$ and IL-2 in $0.41 \%$ of $\mathrm{CD}^{+}{ }^{+} \mathrm{T}$ cells (Figure $4 \mathrm{~A}$, plot 8 ). This represents a 2.6 -fold increase over cells that were precultured for 10 days in the absence of peptide and then stimulated with SARS-CoV-2 $\mathrm{S}$ peptides (Figure 4A, plot 
Table 1. HCoV-NL63 T cell-targeted peptides detected by ELISPOT assay and HLA-binding predictions

\begin{tabular}{|c|c|c|c|c|c|}
\hline HD ID (HLA alleles) & $\begin{array}{l}\text { Peptide } \\
\text { number }\end{array}$ & $\begin{array}{l}\text { Amino acid } \\
\text { number }\end{array}$ & $\begin{array}{l}\text { Targeted peptide (predicted optimal } \\
\text { epitope underlined) }\end{array}$ & $\begin{array}{l}\text { Predicted HLA-restricting } \\
\text { alleles }\end{array}$ & $\begin{array}{l}\text { SFU } / 10^{6} \\
\text { PBMCs }\end{array}$ \\
\hline \multirow{4}{*}{$\begin{array}{l}\text { HD2 } \\
\text { DRB1*01:01, 07:01, } \\
\text { DRB4* 01:01, } \\
\text { DQA1*02:01/DQB1*02:02 } \\
\text { DQA1*01:01/DQB1*05:01 } \\
\text { DPA1*01:03/DPB1*04:01 }\end{array}$} & $16^{A}$ & $91-107$ & VTNEIGLNASVTLKICK & $\mathrm{DRB}^{*} 07: 01, \mathrm{DRB} 1^{*} 01: 01$ & 26 \\
\hline & 75 & $442-458$ & FEKLQCEHLQFGLQDGF & DRB4*01:01, DPA1*01:03/DPB1*04:01 & 48 \\
\hline & 161 & $956-972$ & ARLNYVALQTDVLQQENQ & $\mathrm{DQA1}{ }^{*} 02: 01 / \mathrm{DQB} 1^{*} 02: 02, \mathrm{DRB} 1^{*} 01: 01$ & 30 \\
\hline & 166 & $986-1002$ & IVASFSSVNDAITQTAE & $\mathrm{DQA1}{ }^{*} 02: 01 / \mathrm{DQB} 1^{*} 02: 02, \mathrm{DRB} 1^{*} 07: 01$ & 26 \\
\hline $\begin{array}{l}\mathrm{DRB3}{ }^{*} \text { 02:02, } \\
\mathrm{DQA1} \text { 01:01/DQB1*05:01, }\end{array}$ & 147 & $873-889$ & LEDLLFSKVVTSGLGTV & DRB1*01:03, DRB1*13:05 & 30 \\
\hline
\end{tabular}

DQA1*05:05/DQB1*03:01,

$\mathrm{DPA} 1^{*} 01: 03 / \mathrm{DPB1}{ }^{*} 02: 01$

$\mathrm{DPA} 1^{*} 01: 03 / \mathrm{DPB} 1^{*} 04: 01$

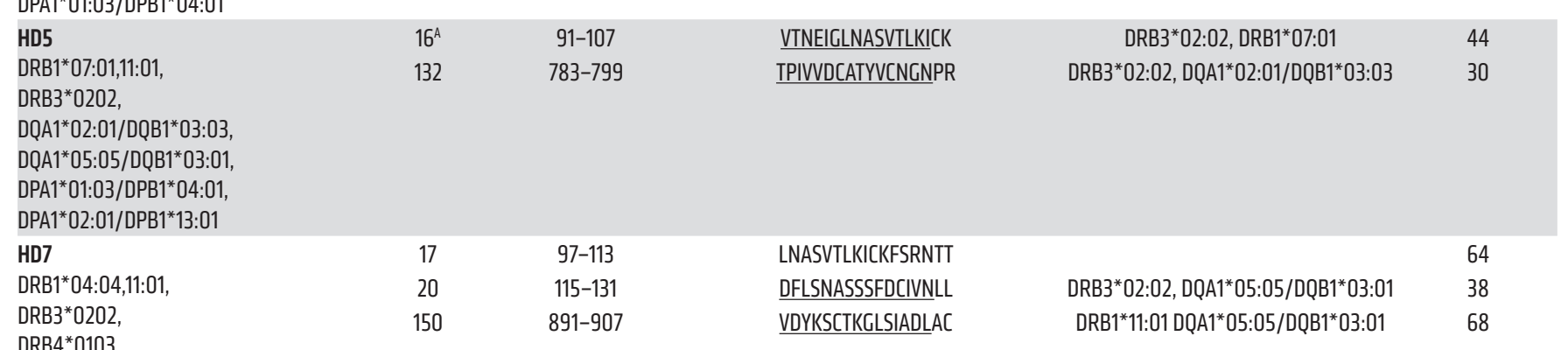

DRB4*0103,

DQA ${ }^{*} 03: 01 / D Q B 1^{*} 03: 02$,

DQA1*05:05/DQB1*03:01,

DPA1*01:03/DPB1*06:01,

DPA1*02:01/DPB1*14:01

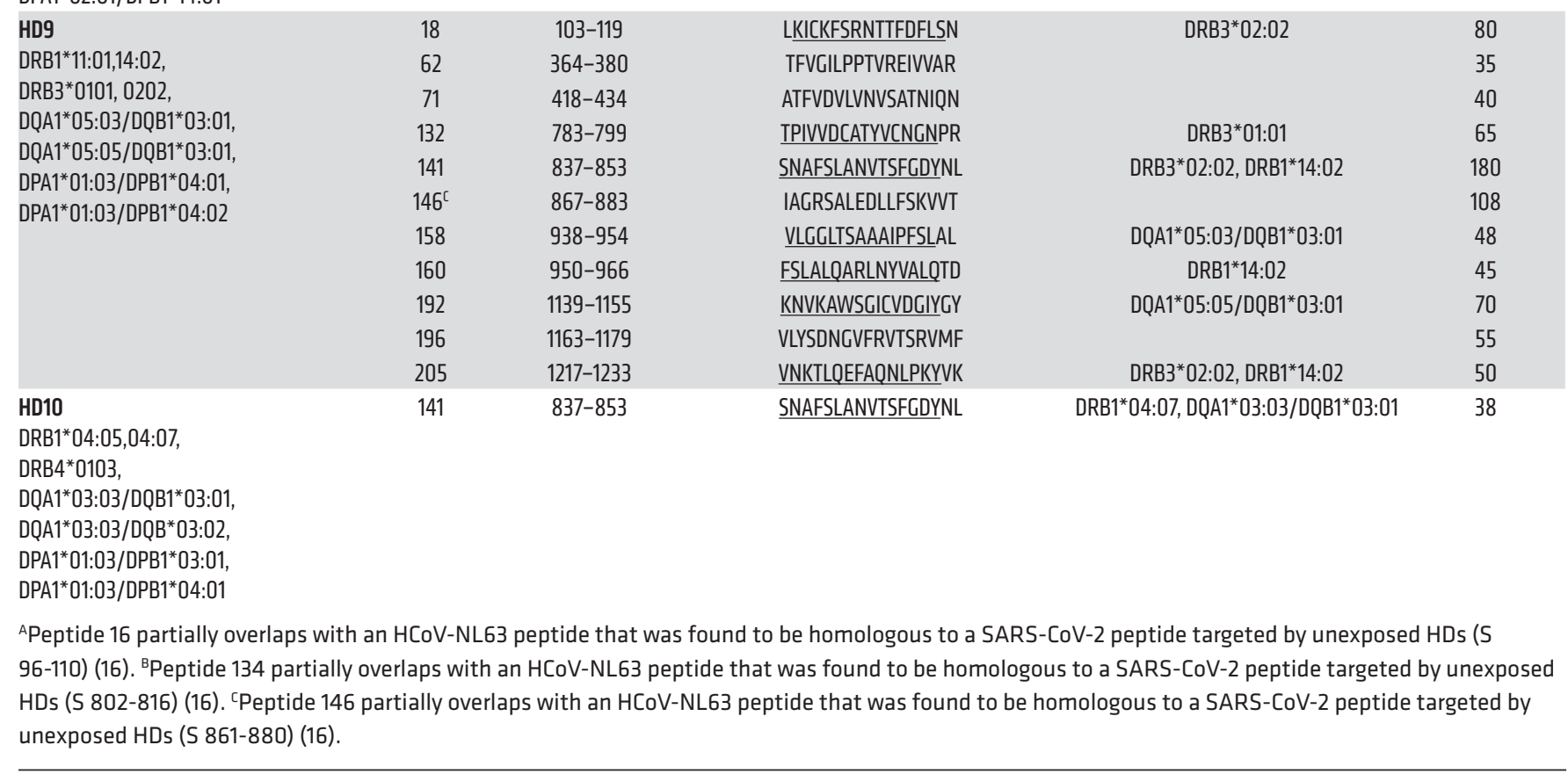

4). Of note, we observed no increase in the percentage of cells that recognized SARS-CoV-2 N peptides following preculturing with the HCoV-NL63 S peptide pool (Figure 4A, plot 7 vs. plot 3), suggesting that the increase in SARS-CoV-2 $\mathrm{S}$ peptide-reactive cells was not due to nonspecific stimulation. Thus, it is likely that there was $\mathrm{CD} 4^{+} \mathrm{T}$ cell cross-recognition of S peptides from the 2 viruses. We observed similar 2.6- and 3-fold increases in antigen-respon- sive $\mathrm{CD} 4^{+} \mathrm{T}$ cells when PBMCs precultured with SARS-CoV-2 S peptides for 10 days were restimulated with SARS-CoV-2 (Figure 4A, plot 16 vs. plot 4) and HCoV-NL63 (Figure 4A, plot 14 vs. plot 2) $S$ peptide pools, respectively, which is further evidence of $T$ cell cross-recognition in HD9.

We performed the same experiment with PBMCs from a CCP (CCP2). Preculturing of PBMCs with HCoV-NL63 S pep- 

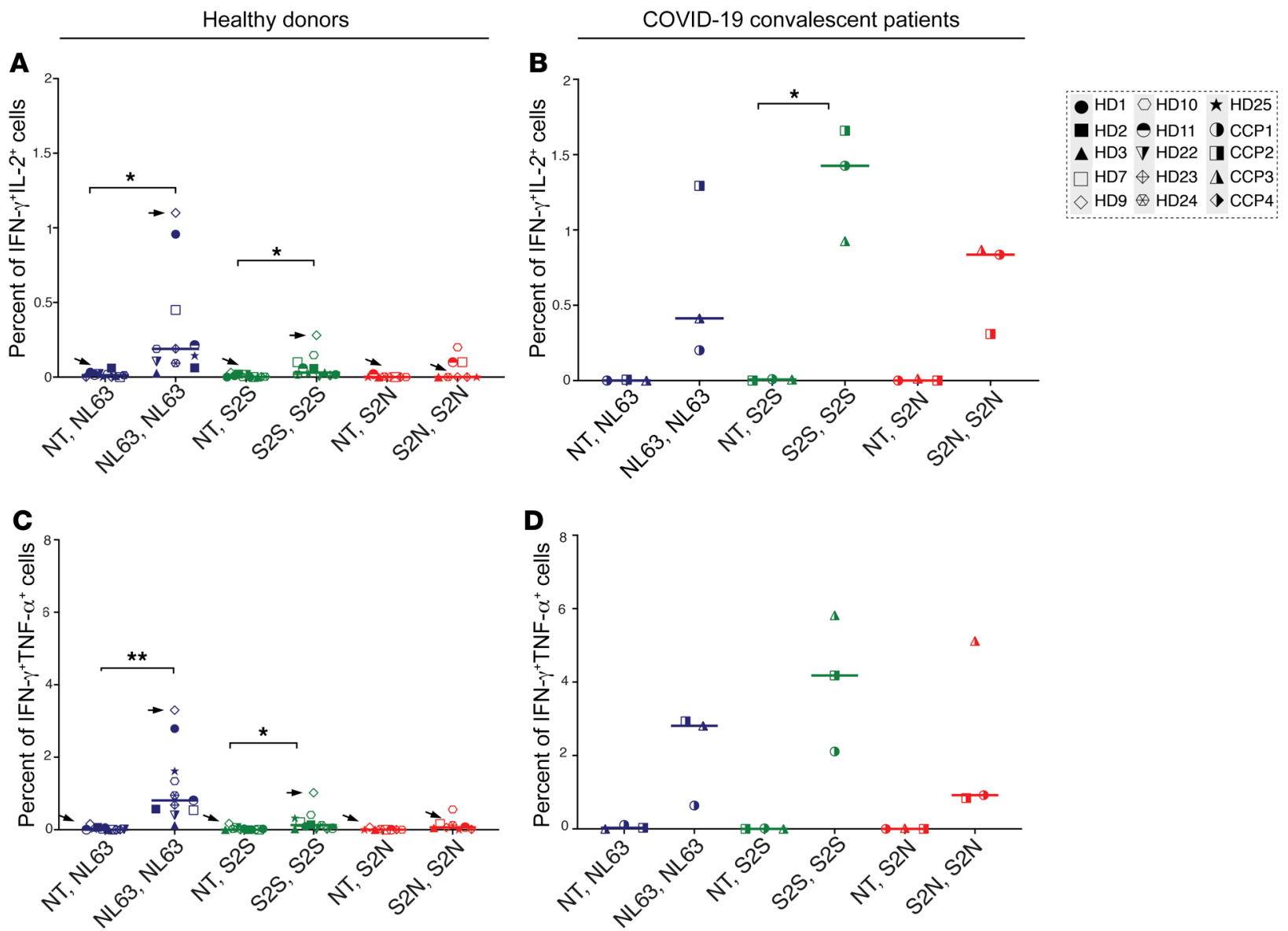

Figure 3. Expansion of antigen-specific $\mathbf{C D 4}^{+} \mathbf{T}$ cell responses. The percentages of cells that coexpressed either IL- 2 and IFN- $\gamma(\mathbf{A}$ and $\mathbf{B})$ or TNF- $\alpha$ and IFN- $\gamma(\mathbf{C}$ and $\mathbf{D})$ are shown for cells from HDs (A and $\mathbf{C})$ and CCPs (B and $\mathbf{D})$ following preculturing for 10-12 days and stimulation for 12 hours with varied peptide pools ( $n=11 \mathrm{HDs} ; n=3$ CCPs). In each panel, the peptide pool used for preculturing is shown first, followed by the peptide pool used in the 12-hour stimulation. ${ }^{*} P=0.0332$ and ${ }^{*} P=0.0021$, by 2-tailed, paired Student's $t$ test. Horizontal bars represent the median. NT, untreated; NL63, HCoV-NL63; S2N, SARS-CoV-2-N; S2S, SARS-CoV-2-S.

tides resulted in 42.6- and 10.0-fold increases in the percentage of cells that responded to restimulation with HCoV-NL63 (Figure $4 \mathrm{~B}$, plot 22 vs. plot 18 ) and SARS-CoV-2 S peptides (Figure 4B, plot 24 vs. plot 20), respectively. Interestingly, while preculturing of the PBMCs with the SARS-CoV-2 S peptide resulted in a 76.8-fold increase in the percentage of cells that responded to restimulation with the SARS-CoV-2 S peptide pool (Figure 4B, plot 32 vs. plot 20), no such increase was seen in the percentage of $\mathrm{CD} 4^{+} \mathrm{T}$ cells that responded to restimulation with HCoV-NL63 S peptides (Figure $4 \mathrm{~B}$, plot 30 vs. plot 18$)$. Thus, the memory $\mathrm{CD} 4^{+} \mathrm{T}$ cells that were amplified by the $S$ peptides from the 2 viruses most likely had different $\mathrm{T}$ cell receptor repertoires with different cross-recognition capacities. We obtained similar cross-recognition results with PBMCs from another CCP, CCP3 (Supplemental Figure 2), and in this case, preculturing of PBMCs with SARS-CoV-2 $\mathrm{S}$ peptides also resulted in cross-recognition of the NL63 S peptide pool.

We generally did not see amplification of $\mathrm{HD} \mathrm{CD} 8^{+} \mathrm{T}$ cell responses after preculturing with $\mathrm{HCoV}-\mathrm{NL} 63 \mathrm{~S}$ or SARS-CoV-2 S or N peptide pools (Supplemental Figure 3). However, $\mathrm{CD} 8^{+} \mathrm{T}$ cells coexpressing TNF- $\alpha$ and IFN- $\gamma$ in response to SARS-CoV S and N peptide pools were amplified in CCP3 in the expansion assay, and there was again evidence of cross-recognition of HCoV-NL63 and
SARS-CoV-2 $\mathrm{S}$ peptides, suggesting that this phenomenon was not limited to $\mathrm{CD} 4^{+} \mathrm{T}$ cells (Supplemental Figure 2).

\section{Discussion}

In this study, we characterized the frequency of circulating common cold coronavirus-specific CD $4^{+} \mathrm{T}$ cells in COVID-19-negative individuals. We show that many HDs who had not had upper respiratory syndromes in the past few months had a significant percentage of $\mathrm{T}$ cells that targeted the $\mathrm{S}$ protein of 3 common cold coronaviruses. The response to the HCoV-NL63 S protein appeared to be broad, and we identified 22 targeted peptides in this protein.

Several studies have looked for the presence of SARS-CoV-2specific T cells in HDs. Peng et al. found no responses to various peptide pools by ELISPOT assays in 15 HDs from the United Kingdom (13), and Zhu et al. did not detect any baseline ELISPOT responses to $S$ protein peptides in 108 vaccine recipients in China (21). In contrast, using an ELISPOT assay, Sekine et al. found T cells specific for the $\mathrm{S}$ and $\mathrm{M}$, but not $\mathrm{N}$, proteins in HDs in Sweden who donated blood prior to the pandemic (7). Le Bert et al. detected responses to the $\mathrm{N}$ and nonstructural proteins in at least $30 \%$ of HDs in Singapore, also with the ELISPOT assay (8). Using upregulation of Ox40 and CD137 to detect T cell responses in PBMCs col- 
A

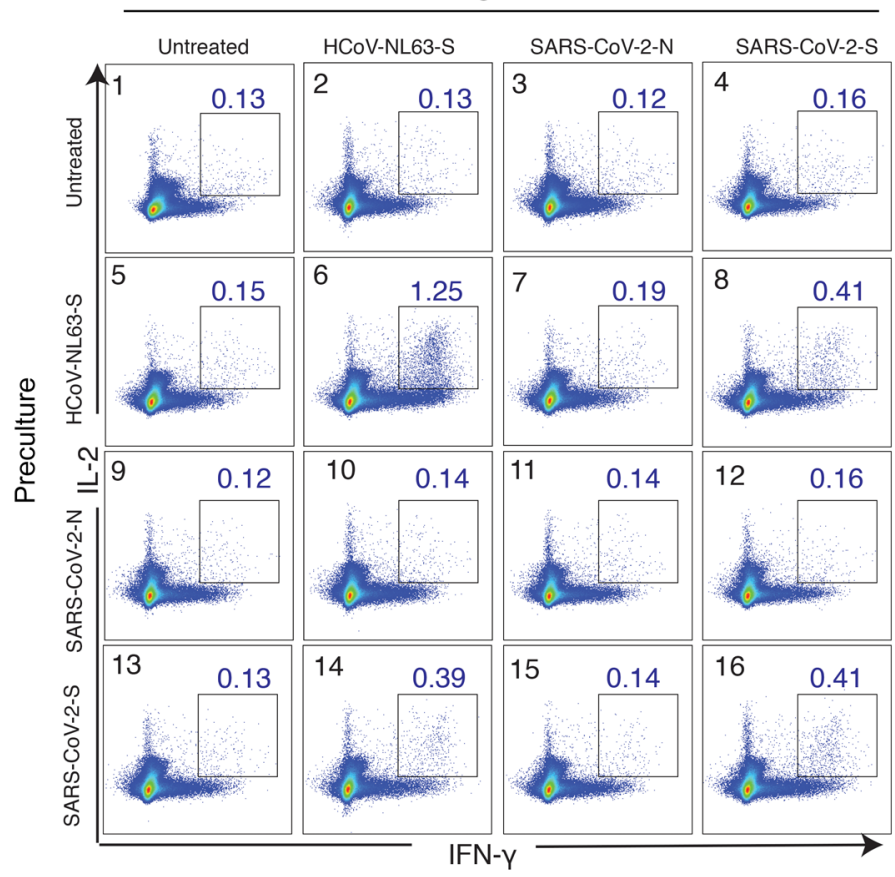

B

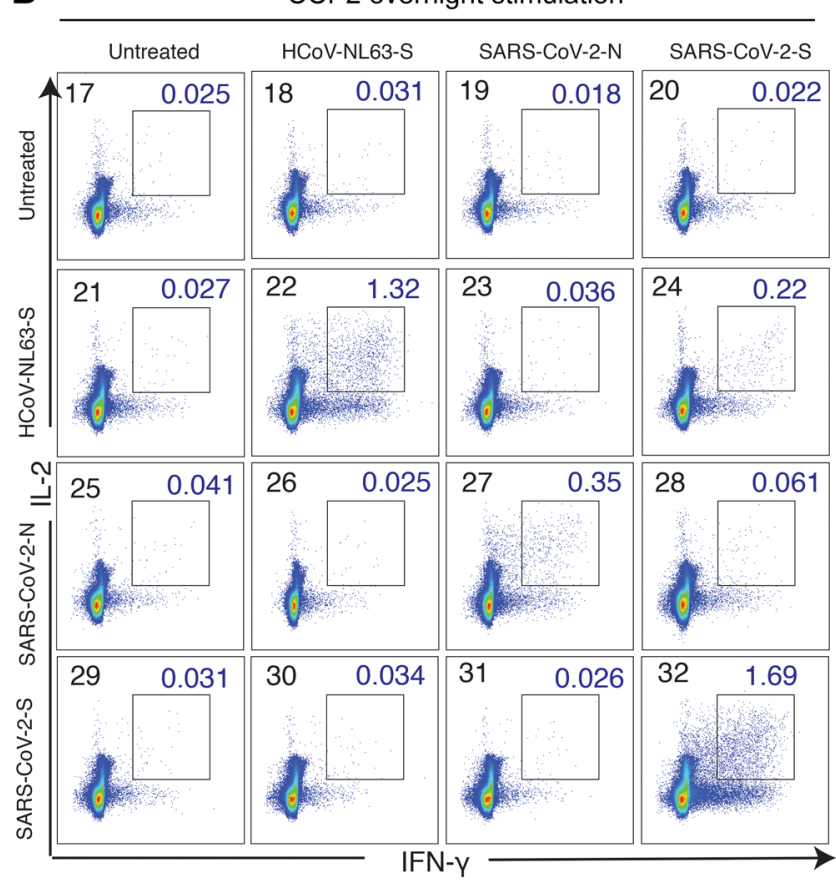

Figure 4. Cross-recognition of HCoV-NL63 and SARS-CoV-2 S protein peptide pools in HD9 and CCP2. PBMCs from HD9 (A) and CCP2 (B) were precultured with peptide pools (shown in rows) for 10-12 days and then stimulated for 12 hours with peptide pools (shown in columns). The percentage of cells that coexpressed IL-2 ( $y$ axis) and IFN- $\gamma$ ( $x$ axis) is shown above the gated box in the upper right corner of each plot.

lected prior to the pandemic, Grifoni et al. found that $\mathrm{CD} 4^{+} \mathrm{T}$ cells from $40 \%-60 \%$ of donors in the United States reacted to SARSCoV-2 peptides (6). Weiskopf et al. found that $\mathrm{CD} 4^{+} \mathrm{T}$ cells from 2 of 10 HDs in the Netherlands upregulated CD69 and CD137 in response to SARS-CoV-2 peptides (11). Similarly, Braun et al. found that $35 \%$ of their HDs in Germany had $\mathrm{CD}^{+} \mathrm{T}$ cell responses to SARS-CoV-2 spike protein peptide pools as determined by upregulation of 4-1BB and CD4OL (9). The reason for this baseline reactivity and the difference in the frequency of HDs with preexisting immunity to SARS-CoV-2 is unclear, but differences in exposure to common cold coronaviruses and potential cross-reactivity between T cells specific for these viruses and SARS-CoV-2 have been postulated as a possible explanation. Although we did not analyze responses to the nonstructural proteins, we show here that most of our HDs did not have detectable responses to SARS-CoV-2 $\mathrm{M}, \mathrm{N}$, or S peptide pools by ELISPOT in spite of having detectable responses to 2 or 3 common cold coronaviruses. However, preculturing of cells with $\mathrm{S}$ peptide pools resulted in a modest but significant $(P=0.03)$ increase in the frequency of T cells that responded to these peptides, suggesting that memory $\mathrm{T}$ cell responses existed in some HDs. Although it is also possible that these were de novo responses, the expansion assay we used did not involve the stimulation of T cells with isolated DCs, and in prior experiments, we were unable to generate de novo responses to peptides (22).

Mateus et al. recently mapped out thirty-one SARS-CoV-2 S protein epitopes that were targeted by $\mathrm{T}$ cell lines from unexposed HDs (16). They showed that the homologous peptides in the S protein from the common cold coronaviruses were also recognized. These data suggest that this cross-recognition of viral epitopes by
$\mathrm{T}$ cells can explain the preexisting immunity seen in some of their study participants. Notably, 28 of 31 of the homologous HCoVNL63 S protein peptides identified by this approach were not targeted by $\mathrm{CD}^{+}{ }^{+} \mathrm{T}$ cells from the $6 \mathrm{HDs}$ we tested, and this difference may partially explain the low number of individuals with preexisting SARS-CoV-2 immunity in our cohort. Interestingly, HD9, the only participant in our cohort who responded to SARSCoV-2 peptide pools, had $\mathrm{T}$ cells that made a robust response to an HCoV-NL63 peptide (S 867-883) that overlaps significantly with a homologous HCoV-NL63 peptide (S 861-880) found to be targeted in 2 individuals in the Mateus et al. cohort (16). The S 861-880 peptide was found to have $53 \%$ homology to the SARS-CoV-2S peptide (S 811-825) that elicited $\mathrm{T}$ cell responses in unexposed individuals.

A strength of our study is that we used an unbiased approach and examined the responses to overlapping peptides spanning the entire HCoV-NL63 S protein to determine targeted peptides. This approach is distinct from, and complimentary to, the approach used by Mateus et al., in which epitopes in the 4 common cold coronaviruses were detected by analyzing peptides that had homology to 142 SARS-CoV-2 epitopes (16). Our study is limited by the fact that we did not look at responses to HCoV-HKU1 protein and that we analyzed the responses to just the $\mathrm{S}$ protein. However, in studies in individuals with SARS (23) and COVID-19 $(6,7,9-16)$, the $\mathrm{S}$ protein is quite immunodominant, so it is likely that the responses to the $S$ protein peptides of the common cold coronaviruses we observed were representative of the responses to the entire viral proteome. Another limitation is that, although we analyzed HD responses to SARS-CoV-2 S, M, and N peptide pools, we did not test for reactivity to SARS-CoV-2 nonstructur- 
al proteins. This is important, because some studies have shown responses to peptides from these antigens in unexposed donors (6, $8,16)$. We may also not have detected SARS-CoV-2-specific memory $\mathrm{CD}^{+} \mathrm{T}$ cell responses in more HDs because we used a low concentration of IL-2 in our expansion assay in an effort to minimize nonspecific activation. Finally, we characterized cross-reactive $\mathrm{T}$ cell responses in just 1 unexposed HD, because HD9 was the only unexposed HD in our cohort with preexisting immunity to SARS-CoV-2. Although we screened this individual using 2 different SARS-CoV-2 antibody tests with stated sensitivities of $100 \%$ among hospitalized patients by 3 weeks after symptom onset (24, 25), negative findings do not definitively prove that this individual did not have asymptomatic infection. This is important, given the studies showing that seronegative exposed individuals can have SARS-specific T cell responses $(7,26)$, although the cross-reactivity we describe here may also explain those results.

We believe our data are important, because we interpreted the frequency of circulating SARS-CoV-2-specific effector T cells in HDs in the context of the frequency of $\mathrm{HCoV}$-specific effector T cells. Furthermore, we show directly that in HD9, cross-recognition of SARS-CoV-2 peptides by HCoV-NL63-specific CD4 ${ }^{+}$ $\mathrm{T}$ cells could occur, and this can potentially explain previously described reports of preexisting immunity to SARS-CoV-2 in unexposed individuals, and is consistent with the results of Mateus et al. (16). Further studies in larger cohorts will be needed to determine how common these cross-reactive responses are. It will also be important to determine whether these responses lead to more rapid control of viral replication, thus conferring protection, or whether they contribute to inflammation or suboptimal priming of SARS-CoV-2-naive T cells and lead to poor outcomes.

\section{Methods}

Subjects. Blood samples from healthy laboratory donors and 4 individuals who recovered from COVID-19 were obtained between April and July 2020. All the HDs reported no known exposure to COVID-19 patients and no upper respiratory tract infections over the preceding 3 months. Twelve of the HDs were between the ages of 20 and 29 years, 3 were between the ages of 30 and 39 years, 5 were between the ages of 40 and 49 years, and 1 was between the ages of 50 and 59 years. Thirteen of the HDs were men and 8 were women. We also studied 4 patients who had recovered from COVID-19. Blood was drawn 3 months after the onset of their symptoms. Three were previously healthy and had mild disease courses (CCP1, CCP3, CCP4), and 1 participant with well-controlled HIV-1 infection on antiretroviral therapy had a severe disease course (CCP2). For all experiments, PBMCs were collected from whole blood after Ficoll-Paque PLUS gradient centrifugation (GE Healthcare Life Sciences). For some experiments, CD8 ${ }^{+} \mathrm{T}$ cells were depleted using Miltenyi Biotec CD8 ${ }^{+} \mathrm{T}$ Cell Positive Selection Kits. High-resolution class II typing was performed on PBMCs from 6 HDs at the Johns Hopkins Hospital Immunogenetics Laboratory. The Immune Epitope Database and Analysis Resource (http://www.iedb.org) was used for optimal epitope and HLA-binding predictions using recommended parameters (27).

Peptides and ELISPOT assays. Peptides for the $\mathrm{S}$ protein of $\mathrm{HCoV}-$ NL63, HCoV-229E, HCoV-OC43, and SARS-Cov-2, as well as the M and $\mathrm{N}$ proteins of SARS-CoV-2 were obtained from BEI Resources and were reconstituted with DMSO at a concentration of $10 \mathrm{mg} / \mathrm{mL}$. The
HCoV-229E S protein peptide pool has 195 peptides consisting of 17 mer with 11 amino acid overlaps. The HCoV-NL63 S protein peptide pool has 226 peptides made up of 14-17 mer with 11-13 amino acid overlaps. The HCoV-OC43 S protein peptide pool has 226 peptides made up of 17 or 18 mer with 11 amino acid overlaps. The SARS-CoV-2 peptides are 12 mer, 13 mer, or 17 mer, with 10 amino acid overlaps. The $\mathrm{S}$ protein peptide pool was made up of 181 peptides, the $\mathrm{N}$ protein peptide pool was made up of 59 peptides, and the $\mathrm{M}$ peptide pool was made up of 31 peptides. All the peptides were combined into 1 pool for each viral protein. Pools of 10 peptides were made for the HCoV-NL63 $S$ protein, and 1 pool had 17 peptides. Peptides for CEF were obtained from Anaspec. The pool consisted of thirty-two 8-12 mer peptides. Stimulation with anti-CD3 antibody (Mabtech, $1 \mu \mathrm{g} / \mathrm{mL}$ ) was used as a positive control for each study participant.

IFN- $\gamma$ ELISPOT assays were performed as previously described $(28,29)$. Briefly ELISPOT Pro and ELISPOT Plus kits with precoated plates were purchased from Mabtech. The wells were plated with unfractionated PBMCs or CD8 ${ }^{+} \mathrm{T}$ cell-depleted PBMCs at 250,000 cells/well, and the cells were cultured for 22-24 hours with $\mathrm{HCoV}$ peptides at a concentration of $10 \mu \mathrm{g} / \mathrm{mL}$ or with CEF peptides at a concentration of $3 \mu \mathrm{g} / \mathrm{mL}$. The plates were then processed according to the manufacturer's protocol and read by a blinded independent investigator using an automated reading system. Four replicates per pool were run for the comparison of the different viral proteins. The replicate furthest from the median was not used. If 2 values were equally distant from the median, then the higher value was discarded. Two replicates were run for the HCoV-NL63 $S$ protein pools that examined the breadth of the $\mathrm{T}$ cell responses. For epitope mapping, each individual peptide present in a pool was tested in duplicate wells. A peptide was only considered to be positive if both wells had values that were at least twice the average of the untreated wells and the average stimulation index was above 3 and more than $20 \mathrm{SFU} / 10^{6}$ cells were present.

Expansion culture assay. PBMCs $\left(10^{7}\right.$ cells) were cultured in R10 media with $10 \mathrm{U} / \mathrm{mL} \mathrm{IL-2}$ and $5 \mu \mathrm{g} / \mathrm{mL}$ peptides for $10-12$ days in a modified version of a previously described assay (22). The media were not changed during this period. The cells were then washed and replated in fresh $\mathrm{R} 10$ with $10 \mathrm{U} / \mathrm{mL}$ IL-2 and rested 1 day before they were stimulated again with $5 \mu \mathrm{g} / \mathrm{mL}$ peptide with protein transport inhibitors (GolgiPlug, $1 \mu \mathrm{g} / \mathrm{mL}$; GolgiStop, $0.7 \mu \mathrm{g} / \mathrm{mL}$ ) as well as an antibody against CD107a (FITC, clone H4A3) and antibodies against CD28 and CD49d (all from BD Biosciences). After a 12-hour incubation, the cells were washed and stained with annexin V (BV-421, BD Biosciences, 563973) and antibodies against CD3 (APC-Cy-7, BioLegend, 300426), CD4 (PerCP-CY-5.5, BioLegend, 300530), CD8 (BV-605, BioLegend, 301040), and CD107a (FITC, BD Biosciences, 555800). The cells were then fixed, permeabilized, and stained intracellularly for the following cytokines: TNF- $\alpha$ (PE-Cy-7, BD Biosciences, 557647), IFN- $\gamma$ (APC, BD Biosciences, 506510), and IL-2 (PE, BioLegend, 500307). Flow cytometry was performed on a BD FACS LSR Fortessa flow cytometer, and data were analyzed using FlowJo, version 10. Data on a minimum of 100,000 events in the lymphocyte gate were collected and analyzed.

Serology. Donors were tested for SARS-CoV-2-specific antibodies with a rapid $\operatorname{IgG} / \operatorname{IgM}$ combined antibody prescreening kit (sensing. self). Plasma from HD9 was also tested for SARS-CoV-2 IgG and IgA antibodies at the Johns Hopkins Hospital clinical laboratory to confirm seronegative status. 
Statistics. All statistical analyses were performed using GraphPad Prism 8.4.3 (GraphPad Software). For experiments requiring multiple comparisons, a 1-way ANOVA with Geisser-Greenhouse correction was used. Dunnett's multiple-comparison test was used to determine difference between groups. For experiments requiring comparisons between 2 groups, a 2-tailed, paired Student's $t$ test was used to determine significance. A $P$ value of less than 0.05 was considered statistically significant.

Study approval. The study was approved by the IRB of Johns Hopkins University. Written informed consent was obtained from all study participants prior to their inclusion in the study.

\section{Author contributions}

BAW and AKK performed the experiments and wrote the manuscript. CCG performed experiments. OL provided reagents.
SCR analyzed data. JNB supervised experiments and wrote the manuscript.

\section{Acknowledgments}

We thank all the study participants, who donated blood. We also thank George Mwinnyaa, Mikella Vermaire, Eileen Scully, and Yolanda Arthur for helpful discussions. This work was supported by the Johns Hopkins University Center for AIDS Research (P30AI094189), the NIAID, NIH (R01AI120024, to JNB), and the Division of Intramural Research, NIAID, NIH (to OL).

Address correspondence to: Joel N. Blankson, Johns Hopkins University, 855 N. Wolfe Street, Rangos 552, Baltimore, Maryland 21205, USA. Phone: 410.502.9920; Email: jblanks@jhmi.edu.
1. Ogimi C, Kim YJ, Martin ET, Huh HJ, Chiu CH, Englund JA. What's new with the old coronaviruses? J Pediatric Infect Dis Soc. 2020;9(2):210-217.

2. Severance EG, et al. Development of a nucleocapsid-based human coronavirus immunoassay and estimates of individuals exposed to coronavirus in a U.S. metropolitan population. Clin Vaccine Immunol. 2008;15(12):1805-1810.

3. Kiyuka PK, et al. Human coronavirus NL63 molecular epidemiology and evolutionary patterns in rural coastal Kenya. J Infect Dis. 2018;217(11):1728-1739.

4. Galanti M, Shaman J. Direct observation of repeated infections with endemic coronaviruses [published online July 7, 2020]. J Infect Dis. https://doi.org/10.1093/infdis/jiaa392.

5. Callow KA, Parry HF, Sergeant M, Tyrrell DA. The time course of the immune response to experimental coronavirus infection of man. Epidemiol Infect. 1990;105(2):435-446.

6. Grifoni A, et al. Targets of T cell responses to SARS-CoV-2 coronavirus in humans with COVID-19 disease and unexposed individuals. Cell. 2020;181(7):1489-1501.e15.

7. Sekine T, et al. Robust T cell immunity in convalescent individuals with asymptomatic or mild COVID-19 [preprint]. https://doi. org/10.1101/2020.06.29.174888. Posted on bioRxiv June 29, 2020.

8. Le Bert N, et al. SARS-CoV-2-specific T cell immunity in cases of COVID-19 and SARS, and uninfected controls [published online July 15, 2020]. Nature. https://doi.org/10.1038/s41586020-2550-z.

9. Braun J, et al. SARS-CoV-2-reactive T cells in healthy donors and patients with COVID-19 [published online July 29, 2020]. Nature. https:// doi.org/10.1038/s41586-020-2598-9.

10. Meckiff BJ, et al. Single-cell transcriptomic analysis of SARS-CoV-2 reactive CD4 ${ }^{+} \mathrm{T}$ cells [preprint]. https://doi. org/10.1101/2020.06.12.148916. Posted on
bioRxiv June 13, 2020.

11. Weiskopf D, et al. Phenotype and kinetics of SARS-CoV-2-specific T cells in COVID-19 patients with acute respiratory distress syndrome. Sci Immunol. 2020;5(48):eabd2071.

12. Ni L, et al. Detection of SARS-CoV-2-specific humoral and cellular immunity in COVID19 convalescent individuals. Immunity. 2020;52(6):971-977.e3.

13. Peng $\mathrm{Y}$ et al. Broad and strong memory $\mathrm{CD} 4^{+}$and $\mathrm{CD}^{+} \mathrm{T}$ cells induced by SARS-CoV- 2 in UK convalescent COVID-19 patients [preprint]. https:// doi.org/10.1101/2020.06.05.134551. Posted on bioRxiv June 8, 2020.

14. Neidleman J, et al. SARS-CoV-2-specific T cells exhibit phenotypic features of robust helper function, lack of terminal differentiation, and high proliferative potential [published online August 9, 2020]. Cell Rep Med. https://doi. org/10.1016/j.xcrm.2020.100081.

15. Giménez E, et al. SARS-CoV-2-reactive interferon- $\gamma$-producing $\mathrm{CD}^{+} \mathrm{T}$ cells in patients hospitalized with coronavirus disease 2019 [published online Jun 24, 2020]. J Med Virol. https://doi. org/10.1002/jmv.26213.

16. Mateus J, et al. Selective and cross-reactive SARSCoV-2 $\mathrm{T}$ cell epitopes in unexposed humans [published online August 4, 2020]. Science. https://doi.org/10.1126/science.abd3871.

17. Kroemer M, et al. COVID-19 patients display distinct SARS-CoV-2 specific T-cell responses according to disease severity [published online August 24, 2020]. J Infect. https://doi. org/10.1016/j.jinf.2020.08.036

18. Sattler A, et al. SARS-CoV-2 specific T-cell responses and correlations with COVID-19 patient predisposition [published online August 24, 2020]. JClin Invest. https://doi.org/ 10.1172/JCI140965.

19. Rodda LB, et al. Functional SARS-CoV-2-specific immune memory persists after mild COVID-19 [preprint]. https://doi.org/10.1101/2020.08.11.2
0171843. Posted on medRxiv August 15, 2020.

20. Snyder TM, et al. Magnitude and dynamics of the T-cell response to SARS-CoV-2 infection at both individual and population levels [preprint]. https://doi.org/10.1101/2020.07.31.20165647. Posted on medRxiv August 4, 2020.

21. Zhu FC, et al. Safety, tolerability, and immunogenicity of a recombinant adenovirus type- 5 vectored COVID-19 vaccine: a dose-escalation, open-label, non-randomised, first-in-human trial. Lancet. 2020;395(10240):1845-1854.

22. Pohlmeyer CW, et al. Cross-reactive microbial peptides can modulate HIV-specific CD ${ }^{+} \mathrm{T}$ cell responses. PLoS ONE. 2018;13(2):e0192098.

23. Li CK, et al. $\mathrm{T}$ cell responses to whole SARS coronavirus in humans. JImmunol. 2008;181(8):5490-5500.

24. Conklin SE, et al. Evaluation of serological SARSCoV-2 lateral flow assays for rapid point of care testing [preprint]. https://doi.org/10.1101/2020.07 .31.20166041. Posted on medRxiv August 4, 2020.

25. Van Elslande J, et al. Antibody response against SARS-CoV-2 spike protein and nucleoprotein evaluated by 4 automated immunoassays and 3 ELISAs [published online July 31, 2020]. Clin Microbiol Infect. https://doi.org/10.1016/ j.cmi.2020.07.038.

26. Gallais F, et al. Intrafamilial exposure to SARS$\mathrm{CoV}-2$ induces cellular immune response without seroconversion [preprint]. https://doi.org/10.11 01/2020.06.21.20132449. Posted on medRxiv June 22, 2020.

27. Vita R, et al. The Immune Epitope Database (IEDB): 2018 update. Nucleic Acids Res. 2019;47(D1):D339-D343.

28. Kwaa AKR, Talana CAG, Blankson JN. Interferon alpha enhances NK cell function and the suppressive capacity of HIV-specific CD8 ${ }^{+}$T cells. J Virol. 2019;93(3):e01541-18.

29. Veenhuis RT, et al. Long-term remission despite clonal expansion of replication-competent HIV-1 isolates. JCI Insight. 2018;3(18):e122795. 